\title{
La excepción del contrato no cumplido en materia concursal en España
}

\author{
Sebastián Bozzo Hauri*
}

\begin{abstract}
RESUMEN
El trabajo estudia la posibilidad de ejercitar la excepción de contrato no cumplido una vez que se declara el concurso de acreedores en el sistema jurídico español. Así, se examina qué efectos se producen sobre los contratos bilaterales con obligaciones recíprocas una vez declarado el concurso de acreedores, cuestión importante para estudiar posteriormente la admisibilidad o no del ejercicio de la exceptio. Se consideran además posibles limitaciones a su ejercicio, como también la posibilidad de ejercitar la exceptio non adimpleti contractus por riesgo de incumplimiento. El estudio pretende precisar el verdadero alcance de la excepción de contrato no cumplido una vez que el contratante in bonis se enfrenta ante la compleja situación del concurso de su contraparte.
\end{abstract}

Excepción de contrato no cumplido - resolución del contrato - acción resolutoria

\section{The breach of contract in bankruptcy in Spain}

\begin{abstract}
This paper analyzes the possibility of bringing a defence based on breach of contract once bankruptcy has been declared in the Spanish legal system. Thus, it examines the effects of bankruptcy on bilateral contracts with reciprocal obligations, which is an important issue for further study of the admissibility of the exceptio. It also considers possible limitations on its use, as well as the possibility of exercising the exceptio non adimpleti contractus for default risk. The study aims to clarify the true scope of this defence once the contractor in bonis is faced with the complex situation of the bankruptcy of its counterpart.
\end{abstract}

Defence of breach of contract - termination of contracts - "acción resolutoria"

* Abogado, Magíster y Doctor en Derecho. Profesor de Derecho Civil Universidad Autónoma de Chile, Pedro de Valdivia 641, Providencia, Santiago, Chile. Correo electrónico: sebastianbozzo@gmail.com

Artículo recibido el 25 de marzo de 2013 y aceptado para su publicación por el Comité Editorial el 29 de mayo de 2013. 


\section{INTRODUCCIÓN}

$\mathrm{D}$ eclarado el concurso, es normal que el deudor (concursado) pueda tener relaciones jurídicas vigentes con terceros, es decir, principalmente contratos pendientes de ejecución por una de las partes o ambas a la vez. Por lo tanto, se plantea el problema de determinar cuál es el efecto que genera la declaración de concurso sobre los contratos, pues según las consecuencias que se deriven de la misma, será posible conocer la suerte que correrán los contratos celebrados entre las partes.

En este sentido, la Ley Concursal $22 / 2003^{1}$ (a futuro a citarse como LC) en su artículo $61.2^{2}$ establece dos reglas que, en principio, pueden parecer contradictorias. La primera, parte de la base que la declaración de concurso no produce por sí sola, en principio, ningún efecto sobre los contratos con obligaciones recíprocas pendientes de cumplimiento. Es decir, no afecta la vigencia de los contratos. Esta regla se complementa con la que declara que se tienen por no puestas las cláusulas contractuales de resolución o extinción del contrato en caso de la declaración de concurso, aunque se permite la aplicación de normas legales que dispongan la extinción o expresamente faculten a las partes para pactarla o para denunciar el contrato (artículo $61.3 \mathrm{LC})^{3}$.

${ }^{1}$ La referencia final del párrafo segundo del art. $61 \mathrm{LC}$ a la resolución de los contratos de arrendamiento financiero ha sido introducida por la Ley 28/2011 de 10 de octubre, de reforma de la Ley 22/2003 de 9 de julio. 2 El artículo 61 de la Ley Concursal 22/2003, señala: “1. En los contratos celebrados por el deudor, cuando al momento de la declaración de concurso una de las partes hubiere cumplido íntegramente sus obligaciones y la otra tuviese pendiente el cumplimiento total o parcial de las recíprocas a su cargo, el crédito o la deuda que corresponda al deudor se incluirá, según proceda, en la masa activa o en la pasiva del concurso.

2. La declaración de concurso, por sí sola, no afectará a la vigencia de los contratos con obligaciones recíprocas pendientes de cumplimiento tanto a cargo del concursado como de la otra parte. Las prestaciones a que esté obligado el concursado se realizarán con cargo a la masa.

No obstante lo dispuesto en el párrafo anterior, la administración concursal, en caso de suspensión, o el concursado, en caso de intervención, podrán solicitar la resolución del contrato si lo estimaren conveniente al interés del concurso. El secretario judicial citará a comparecencia ante el juez al concursado, a la administración concursal y a la otra parte en el contrato y, de existir acuerdo en cuanto a la resolución y sus efectos, dictará auto declarando resuelto el contrato de conformidad con lo acordado. En otro caso, las diferencias se sustanciarán por los trámites de incidente concursal y el juez decidirá acerca de la resolución, acordando, en su caso, las restituciones que procedan y la indemnización que haya de satisfacerse con cargo a la masa. Cuando se trate de la resolución de contratos de arrendamiento financiero, y a falta de acuerdo entre las partes, con la demanda incidental se acompañará tasación pericial independiente de los bienes cedidos que el juez podrá tener en cuenta al fijar la indemnización”.

3. Se tendrán por no puestas las cláusulas que establezcan la facultad de resolución o la extinción del contrato por la sola causa de la declaración de concurso de cualquiera de las partes”.

${ }^{3}$ Los jueces de lo mercantil y las audiencias, especialmente en el ámbito de los contratos bancarios, han mantenido la ineficacia de las cláusulas contractuales que habilitan al banco a resolver el contrato por la declaración de concurso del cliente. Así, en relación con el contrato de crédito de descuento, SAP Barcelona (15ª), 18-2-2008. Rojo, A, Beltrán, E., Legislación y Jurisprudencia Concursales, Aranzadi, Madrid, 2008, pp. 123 y 126. El AJM 3 Barcelona, de 2-5-2006, en Legislación y Jurisprudencia Concursales, cit., p. 122, reconoce que la declaración de concurso puede suponer para el tráfico económico una pérdida de confianza en el concursado, pérdida de confianza que no puede quedar sujeta a la voluntad de la entidad financiera de cesar o resolver de facto los contratos bancarios o de financiación de cualquier índole que pudiera tener 
A la vez, el mismo artículo en su apartado segundo otorga ciertas prerrogativas al juez (y en algunos casos, a las propias partes contratantes y a la administración concursal), que vienen a alterar el régimen común: declarar la resolución del contrato cuando lo exija el interés del concurso (artículo 61.2-II LC) y enervar la resolución y acordar el cumplimiento del negocio ante el ejercicio de la facultad de resolución por incumplimiento, cuando así lo demande el interés del concurso ${ }^{4}$ (artículo 62.3 LC) ${ }^{5}$.

Es decir, en beneficio del concurso es posible que el juez declare la resolución del contrato sin que exista incumplimiento. Ante el incumplimiento del concursado se podrá enervar la acción resolutoria del contratante in bonis, obligándole a este a seguir adelante con la ejecución del negocio. Además es viable, declarado el concurso, la rehabilitación de ciertos contratos, con la condición de que no se hubiesen iniciado los actos de ejecución de la resolución o de los efectos del vencimiento anticipado por impago, que pueden ser rehabilitados, según la Ley Concursal, en beneficio del concurso (artículos 68 a 70 de LC).

el concursado. Luego, si hay cumplimiento normal por parte del concursado, no solo no cabe resolver, sino que el contrato por mandato del artículo 61.2 sigue vigente.

4 ¿Qué debemos entender por "interés del concurso”? Gómez Mendoza, M., "Vigencia de los contratos con obligaciones recíprocas”, en Comentarios a la legislación concursal (Ley 22/2003 y 8/2003) para la reforma concursal, AA.VV. dirigidos por Pulgar Ezquerra, J., Alonso Ledesma, C., Alonso Ureba A., y Alcover Garau G., Tomo I, Dykinson, Madrid, 2004, p. 2812, sitúa tal interés del concurso en la necesidad de conservar y, en su caso, de potenciar, durante el procedimiento, el valor de los bienes del deudor en beneficio de los acreedores implicados, lo que significa también desprenderse de los bienes y contratos gravosos. Aznar Giner, E.: La resolución del contrato en interés del concurso, Tirant lo Blanch, Valencia, 2010, p. 21, indica que, en su opinión: “...el interés del concurso serán todos aquellos actos o negocios tendentes al normal desenvolvimiento del proceso y mejor cumplimiento de su finalidad, consistente en la satisfacción de los acreedores”. Por su parte, Blasco Gascó, F., Declaración en concurso y contratos, Tirant lo Blanch, Valencia, 2009, p. 39, expone lo siguiente: "Aunque la Exposición de Motivos manifiesta acertadamente que la finalidad del concurso no es el saneamiento de la empresa, sino la satisfacción de los acreedores, no es menos cierto que el procedimiento concursal está actualmente orientado a la conservación de la actividad económica del concursado; incluso en la fase de liquidación se tiende a mantener unidas las unidades productivas de la empresa mediante su enajenación conjunta. Efectivamente, la apuesta del legislador es por el convenio y no por la liquidación, es decir, la apuesta es por la subsistencia de la actividad económica y no por levantar acta de defunción de la misma...". Para ver más sobre el interés del concurso, Vid. Serra Rodríguez, A., "El 'interés del concurso' en la Ley 22/2003, de 11 de julio, concursal", en La dialettica degli interessi nella disciplina delle società per anzioni, p. 445 y sgte. Jovene, Editore, Nápoles, 2011.

${ }^{5}$ Sobre el principio de que la declaración de concurso no afecta a la vigencia de los contratos, Etxarandio Herrera, E, J., Manual de Derecho Concursal, La Ley, Madrid, 2009, p. 469, nos indica que el mencionado principio se bifurca en una importante distinción: “a) La regla propia, para los contratos con obligaciones recíprocas pendientes de cumplimiento, tanto a cargo del concursado como de la otra parte, cuando se precisa las prestaciones del primero a cargo de la masa (art. 61.2. pfo. $1^{\circ}$ LCO), en la lógica de que la masa del concurso recibe un contravalor coetáneo. b) La impropia, pues conforme al artículo 61.1 LCO, indica que en caso de cumplimiento de una de las partes de contrato con obligaciones recíprocas, acreedor o concursado, el crédito o la deuda del concursado se incorporará a la masa activa o pasiva. De este modo, el acreedor in bonis que ha cumplido totalmente su prestación, supuesto que el concursado no haya cumplido la suya, se encuentra deprimido, ya que su crédito será concursal, tanto al vencido antes de la declaración del concurso como el vencido con ulterioridad, aunque la norma no distingue. 
Como indica Moreno Sánchez-Moraleda ${ }^{6}$ : "Ciertos contratos realizados por el deudor han podido quedar resueltos o considerarse vencidos antes de la declaración de concurso a causa de incumplimientos del deudor, explicables por las dificultades financieras y patrimoniales previas a una posible insolvencia que finalmente desembocaron en una declaración de concurso. Tales contratos estaban ya resueltos o considerados vencidos en el momento en que se declara el concurso, pero tal situación, por privar al deudor de ciertos bienes o por aumentar sus dificultades financieras, puede impedir la continuación de su actividad y obstaculizar una solución adecuada del concurso". Por ello, los artículos 68, 69 y 70 de la $\mathrm{LC}^{7}$ permiten que algunos contratos, bajo la condición de que no se hubiesen iniciado los actos de ejecución de la resolución o de los efectos del vencimiento anticipado por impago, puedan ser rehabilitados en beneficio del concurso.

\section{EFECTOS DE LA DEClARACIÓN DE CONCURSO EN LOS CONTRATOS CON OBLIGACIONES RECÍPROCAS}

Para poder determinar la posibilidad de ejercitar la exceptio en materia concursal, creemos necesario, de forma previa, sintetizar cuáles son las consecuencias que se pueden generar en los contratos con obligaciones recíprocas una vez declarado el concurso de acreedores.

a) La declaración en concurso de una de las partes no afecta la vigencia de los contratos con obligaciones recíprocas pendientes total o parcialmente de cumplimiento por las partes (artículo 61.2 LC). Así entonces, como señala Blasco Gascó ${ }^{8}$ : “... el principio, por tanto, es el de vigencia y conservación de los contratos. Así, la norma tiende a garantizar la continuidad de la actividad empresarial o profesional del concursado, frenar el pasivo y acomodar el proceso concursal a los fines de la ejecución colectiva".

b) En caso que se declare el concurso no se priva a las partes de un contrato con obligaciones recíprocas de la facultad resolutoria. En consecuencia, si se produce un posterior incumplimiento por alguna de las partes, se podrá ejercitar la acción resolutoria para poner fin al contrato. De esta manera, si ambas partes se encuentran al corriente en el cumplimiento de sus obligaciones, de modo que la parte in bonis, como analizaremos a continuación, puede ejercitar a su favor la exceptio non

${ }^{6}$ Moreno Sánchez-Moraleda, A., Los efectos de la declaración de concurso en los contratos bilaterales, Tirant lo Blanch, Valencia, 2010, pp. 29 y 30.

${ }^{7}$ El artículo 68 de la LC, se refiere a la posibilidad de rehabilitar los contratos de prestamos y demás de crédito que hayan vencido anticipadamente en los tres meses anteriores a la declaración de concurso por impago de las cuotas de amortización o intereses. A su vez, el artículo 69 de la misma ley indica que se podrán también rehabilitar los contratos de adquisición de bienes muebles e inmuebles con precio aplazado cuya resolución se haya producido tres meses antes a la declaración de concurso. Lo mismo indica el artículo 70 de la LC, para los contratos de arrendamientos urbanos.

${ }^{8}$ Blasco Gascó, F., Declaración en concurso... op. cit., p. 11. 
adimpleti contractus, no podrá solicitar la resolución del contrato mientras el concursado no haya incumplido su obligación una vez llegado el vencimiento?.

c) Por el interés del concurso puede el concursado o la administración concursal solicitar la resolución del contrato, aunque no haya habido incumplimiento por ninguna de las partes.

d) Es posible mantener en vigor el contrato incumplido por el concursado, si, ante la acción de resolución ejercitada por el contratante in bonis, el juez acuerda el cumplimiento del contrato.

e) Las cláusulas de resolución o de extinción del contrato por la mera declaración en concurso de cualquiera de las partes se tiene por no puestas, pero no se impide la aplicación de normas legales que dispongan la extinción del contrato, o que faculten expresamente a las partes para pactarla o para denunciar el contrato.

f) Respecto de los contratos con prestaciones recíprocas parcialmente cumplidas, el artículo 61.1 LC dispone que el crédito a la deuda que corresponda al deudor se incluirá, según proceda, en la masa activa o pasiva del concurso, y el artículo 61.2 LC para los contratos con obligaciones recíprocas pendientes de cumplimiento tanto a cargo del concursado como de la otra parte establece a cargo de la masa las prestaciones a que esté obligado el concursado con arreglo al contrato.

Consecuentemente, como indica Blasco Gascó ${ }^{10}$, la declaración de una de las partes del contrato en concurso no afecta a la vigencia del mismo ni, en principio, al régimen jurídico propio de las obligaciones sinalagmáticas, sino en cuanto dispone expresamente la Ley Concursal ${ }^{11}$.

Ahora bien, solo es posible que se sigan estas consecuencias o efectos cuando se cumplan ciertos presupuestos o requisitos como:

${ }^{9}$ En este sentido, Martínez Rosado, J., "Los efectos de la declaración de concurso sobre los contratos con obligaciones recíprocas (Arts. 61 a 63 de la Ley 22/2003), de 9 de julio concursal”, en Estudios sobre la Ley Concursal. Libro Homenaje a Manuel Olivencia, AA.VV, Tomo III, Marcial Pons, Madrid, 2004, p. 2969. Así la SAP de A Coruña de 28 de julio de 2011 (AC 2011/2123) admite la acción resolutoria ejercitada por la compradora de una vivienda, al entender tanto el juez de primera instancia de lo mercantil como la Audiencia Provincial que el incumplimiento de la promotora es posterior a la declaración de concurso, por ende es plausible declarar la resolución del contrato.

${ }^{10}$ Blasco Gascó, F., Declaración en concurso... op. cit., p. 13. Sánchez Paredes, M.L.: "Los contratos bilaterales pendientes en el concurso", ADCo, núm. 18, 2009, p. 426, indica al respecto: "La regla de mantenimiento de los contratos tras el concurso parece acorde con un procedimiento que establece la necesidad de conservación de la masa activa y de continuidad de la empresa (arts. 43 y 44 LC), que manifiesta su preferencia por la solución convenida -como medio para lograr la finalidad de conservación de la actividad profesional o empresarial del concursado (EX. M. ep. VI) y por la conservación de las empresas o unidades productivas de bienes y servicios integradas en la masa (EX. M. ep. VII). Así lo han entendido los jueces de lo mercantil, al considerar que el mantenimiento de los contratos es fundamental para la continuidad del ejercicio de la actividad empresarial, de ahí que se impida que la mera declaración de concurso permita a la otra parte contratante lograr la resolución del contrato, obviando el principio de vigencia y conservación de los contratos (art. 61.3 LC)".

${ }^{11}$ Así por ejemplo la SAP de A Coruña de 28 de julio de 2011 (AC 2011/2122). 
i) La declaración de concurso.

ii) La perfección de un contrato antes de la declaración de concurso.

iii) Un contrato de cumplimiento exigible a la declaración de concurso.

iv) Un contrato con obligaciones recíprocas.

v) Un contrato con obligaciones pendientes de cumplimiento por ambas partes.

Si no se cumplen estos presupuestos, no se podrá seguir las consecuencias antes indicadas, ya que para la aplicación de los artículos 61 y 62 de la LC es básico que estemos ante los requisitos anteriormente señalados.

\section{AdMISIBILIDAD DE LA EXCEPTIO NON ADIMPLETI CONTRACTUS UNA VEZ DECLARADO EL CONCURSO}

Debido a que el artículo 61 LC establece que la declaración de concurso, por sí sola, no afectará a la vigencia de los contratos con obligaciones recíprocas, no debiera, por lo tanto, alterar tampoco los remedios sinalagmáticos que pone el Derecho al servicio de las partes para mantener dicha vigencia ${ }^{12}$.

Se debe, de esta forma, tener en cuenta las medidas que se adopten o los efectos que puedan surgir como consecuencia de actuaciones en el seno del procedimiento concursal, sí pueden influir en la vigencia del contrato, hasta el punto de ser una causa de extinción del mismo. Igualmente, puede perjudicar a estos contratos la solución que se adopte respecto del cierre de la empresa del concursado. También podrá afectar al cumplimiento del contrato la sentencia de calificación del concurso como culpable, que inhabilite al deudor para el ejercicio de la actividad. Así sucederá, por ejemplo, cuando se trate de un contrato celebrado en atención a las cualidades personales o técnicas de la

${ }^{12}$ Hernández Martí, J., "Efectos de la declaración del concurso: efectos sobre los contratos”, Concurso e insolvencia punible, pp. 264 y 265, Tirant lo Blanch, Valencia, 2004, Vásquez Iruzubieta, C., Comentarios a la Ley Concursal, Art. 61, Dijusa, Madrid, 2003, p. 546. Navarro Castro, M.: Los créditos contra la masa en el concurso de acreedores, Reus, Madrid, 2008, pp. 103 y 104, advierte que la Ley Concursal viene a dejar muy claro que la declaración del concurso, por sí sola, no afectará a la vigencia de los contratos con obligaciones recíprocas pendientes de cumplimiento (artículo 61.2); despejando cualquier duda al respecto sobre que la declaración de concurso no genera de por sí la resolución del contrato. Eso no significa que la situación que se puede crear tras la declaración del concurso no pueda afectar a ciertos contratos. En el derecho anterior ya admitían la oponibilidad de la exceptio en la quiebra: Sánchez Calero, F., Instituciones de Derecho Mercantil, II, McGraw-Hill, Madrid, 2002, p. 445, Vicente Y. Gella, A., Curso de Derecho Mercantil Comparado, Tip. La Académica, Zaragoza, 1960, p. 713, Beltrán Sánchez, E.M., La deuda de la masa, Edizioni Scientifiche italiane, Bolonia, 1986, p. 156 y 157, Fines Ratón, J.M., Los efectos de la declaración de quiebra en los contratos bilaterales, Civitas, Madrid, 1992, pp. 59 y sgtes. Para Trujillo Diez, I.J., Los efectos del concurso sobre el contrato de cuentas corrientes, Aranzadi, Navarra, 2003, pp. 77 y 78: “...pues bien, en España, pese al conflicto que pueda existir entre las facultades de autotutela del acreedor in bonis y la par condictio creditorum, está generalmente admitida la oponibilidad a la quiebra de la exceptio inadempleti contractus, con fundamento en el artículo 1475 C.C, que, aunque se refiere solo a la compraventa a plazos, resulta extensible a toda suerte de contratos bilaterales en los que ninguna de las partes haya cumplido aún sus obligaciones cuando se descubre la insolvencia de uno de los contratantes". 
persona del concursado. Al quedar inhabilitado, no podrá cumplir el contrato y al ser intuitu personae, tampoco podrá hacerlo la administración concursal ${ }^{13}$.

Por todo esto, se puede señalar que el principio que establece la Ley Concursal en el sentido que la declaración de concurso no afectará a la vigencia de los contratos con obligaciones recíprocas pendientes de cumplimiento, se refiere precisamente a que la declaración de concurso en sí misma no influirá a los contratos de este tipo. No obstante es posible adoptar medidas, en el seno del procedimiento concursal, que afecten algunos contratos, como ya hemos indicado ${ }^{14}$.

Ahora bien, esta excepción solo podrá alegarse en los casos de contratos bilaterales pendientes de ejecución, total o parcialmente, por "ambas" partes contratantes, quedando excluido, por tanto, el artículo 61.1. LC. Ello, debido a que este artículo establece en el apartado primero, que: “...si una de las partes hubiera cumplido íntegramente sus obligaciones y la otra tuviese pendiente el cumplimiento total o parcial de las recíprocas a su cargo, el crédito a la deuda que corresponda al deudor se incluirá, según proceda, en la masa activa o en la pasiva del concurso". Así, en el caso que la parte in bonis haya celebrado un contrato con el concursado, y este último ya ha cumplido íntegramente, pierde sentido para el tercero ejercitar la exceptio, pues al hacerla valer no tendrá fundamento ante el correcto cumplimiento del concursado. A diferencia si el contratante in bonis que celebró el contrato con el concursado ya ha cumplido íntegramente con su prestación, solo le queda esperar mediante el procedimiento concursal el cobro de su contraprestación ${ }^{15}$.

Por otra parte, diferenciar si el contrato ha sido cumplido por el contratante in bonis de forma parcial o total tiene una trascendencia sustancial, pues en un caso el crédito del contratante in bonis cumplidor es un crédito concursal, y en el otro el crédito de la parte in bonis se convierte en un gasto prededucible, de manera que la posición de la parte in bonis frente al concurso es mejor si no ha cumplido totalmente su prestación (art. 61.2 LC) que si la ha cumplido (art. 61.1 LC). Será así fundamental determinar en qué situaciones los contratos que ligan a la parte in bonis y a la parte concursada están pendientes de cumplimiento por ambas o solo por una de ellas ${ }^{16}$. De esta manera, a la

${ }^{13}$ Martínez Flórez, A., "Vigencia de los contratos..., op. cit., pp. 1143 y 1144.

${ }^{14}$ Los juzgados acogen estos razonamientos en algunas resoluciones que contemplan la extinción del contrato en "interés del concurso" (art. 61.2-2 ${ }^{\circ}$ LC). En la sentencia del juzgado de lo mercantil de Alicante, 19 de junio de 2008, ADCo, nº 13 (2008-1), p. 443, se dice: “...es evidente que conviene al interés superior del concurso poner fin a una relación contractual por la que se obtiene el uso temporal de una maquinaria que actualmente no está destinada a la actividad empresarial, que ha cesado". En palabras de la sección $15^{a}$ de la Audiencia Provincial de Barcelona (auto de 22-11-2006, Legislación y Jurisprudencia Concursales, cit., p. 122), “...la vigencia de los contratos no se ve afectada per se por la declaración de concurso, sin perjuicio que a prevalencia del interés del concurso se concrete, por la administración concursal o por el mismo concursado, según los casos, en la resolución del contrato por incumplimiento posteriores, en la resolución de los contratos de tracto sucesivo por incumplimiento de deudas anteriores a la declaración, en una solicitud de resolución contractual o en una solicitud de mantenimiento del contrato resoluble".

${ }^{15}$ En este sentido, Finez Ratón, J. M., "De los efectos sobre los contratos", en Tratado Práctico Concursal, Tomo II, Efectos de la Declaración de Concurso, dir. Pedro Prendes Carril, Aranzadi, Navarra, 2009, p. 625.

${ }^{16}$ Sánchez Paredes, M. L., "Los contratos bilaterales pendientes en el concurso”, op. cit., p. 427. 
parte in bonis, en supuestos dudosos, le interesará defender que el contrato está pendiente de cumplimiento por ambas partes ${ }^{17}$.

Así lo entiende, además, la sentencia del juzgado mercantil núm. 1 de Bilbao de 1 de septiembre de $2005^{18}$, que conociendo incidente concursal de resolución de contrato de compraventa interpuesto por el contratante in bonis en contra de la concursada, por considerar que entregada la mercancía no fue satisfecho el precio. Al respecto, el demandante mantiene que los arts. 61.2 y 62.1 de la LC le autorizan a resolver el contrato que había suscrito con la concursada, porque ha cumplido por su parte con lo que le incumbe, y no ha hecho otro tanto la parte demandada, considerando entonces aplicable el art. 1124 del CC referente a la resolución de los contratos, lo que a su juicio justifica que haya de reintegrarse el objeto del contrato suscrito. La sentencia al respecto señala: “...Sin embargo la Ley Concursal ha establecido un régimen específico, que es además sustento del propio proceso concursal, que no autoriza a una pretensión semejante. El art. 61 al disciplinar la vigencia de los contratos con obligaciones recíprocas, establece en su apartado primero que, en los casos en que una de las partes hubiera cumplido íntegramente sus obligaciones y la otra tuviera pendiente el cumplimiento total o parcial de las recíprocas, el crédito o la deuda que corresponda al deudor se incluirá, según proceda, en la masa activa o pasiva del concurso. Esto sucede precisamente en este supuesto, en el que el contratante in bonis ha satisfecho en su totalidad la prestación, y ante el incumplimiento de la concursada, intentó antes de la declaración de concurso hacer efectivo el precio, que era la contraprestación, acudiendo al juzgado de primera instancia de Cistierna a tratar de hacer eficaz los títulos cambiarios que se le habían entregado para pago. Al aplicar esta regla el efecto que se produce es que el demandante se convierte en un acreedor más de los que integran la masa pasiva del concurso, y tendrá el mismo trato que los demás sin perjuicio de la calificación concursal de su crédito".

17 Monserrat Valero, A., "Los efectos generales de la declaración de concurso sobre los contratos bilaterales”, ADCo, 2008, núm. 12, p. 73, señala sobre los contratos pendientes de cumplimiento, lo siguiente: "Cuando una de las partes ha cumplido sus obligaciones principales, pero ha incumplido las accesorias, se plantea si, supuesto que la otra parte no ha cumplido íntegramente su obligación, se puede decir que estamos ante un contrato todavía pendiente de ejecución por ambas partes (art. 61.2). Si estamos ante el incumplimiento de una obligación meramente accesoria la respuesta ha de ser negativa. Por ejemplo, si el vendedor hubiera entregado la cosa vendida y no hubiera pagado los gastos de escritura, que tiene pendientes frente al comprador, que los ha adelantado, y este no hubiera pagado el precio, el régimen aplicable es el del 61.1 y no el del 61.2, pues para aplicar este las obligaciones de ambas partes pendientes de cumplimiento han de ser recíprocas. Si existen prestaciones accesorias recíprocas pendientes de cumplimiento por ambas partes, pero una de ellas ha cumplido íntegramente la obligación principal sin que la otra haya cumplido la correspectiva, la falta de cumplimiento de las obligaciones accesorias no puede atraer todo el contrato al régimen del artículo 61.2. Parece más lógico que suceda lo contrario, que el cumplimiento de la obligación principal por una de las partes atraiga la falta de cumplimiento de la obligación accesoria a su régimen, el del 61.1”.

$$
18 \text { AC 2005/1563. }
$$


La excepción de contrato no cumplido podrá ser ejercida por ambas partes en el caso de que exista incumplimiento o un incumplimiento defectuoso por una de las partes, y se exija por la otra su cumplimiento ${ }^{19}$.

De esta forma, por ejemplo, en la ejecución de un contrato de obra por parte del contratista in bonis, y la falta de ejecución total acordada en el contrato, el concurso podrá valerse de los mecanismos de protección frente a dicha prestación defectuosa: excepción de contrato no cumplido regularmente (exceptio non rite adimpleti contractus) ante la pretensión de pago por parte del contratista. Opuesta la exceptio, el deudor (concursado) podrá optar por solicitar, en su demanda reconvencional, la reducción del precio en proporción a la parte de la obra no realizada o mal ejecutada, o reclamar la correcta ejecución de la obra.

Por su parte, el deudor que es demandado por la administración concursal podrá, con el objetivo de mantener el equilibrio patrimonial de las partes en el contrato bilateral, oponerse a su cumplimiento si existe a su vez un incumplimiento o un cumplimiento defectuoso del concursado. La exceptio, en este sentido, es la mejor garantía ante el riesgo de inejecución de la contraparte, riesgo, además, que está totalmente justificado en el caso de apertura de un procedimiento concursal ${ }^{20}$.

Teniendo en cuenta que la declaración de concurso no afecta en principio a la vigencia de los contratos pendientes de cumplimiento por ambas partes, y que las prestaciones a que esté obligado el concursado se realizarán con cargo a la masa ${ }^{21}$, la parte in bonis tendría que aguardar a la satisfacción concursal de su crédito reconocido en el procedimiento en curso, si el órgano de administración le exigiera el cumplimiento íntegro de la prestación pactada.

${ }^{19}$ Martínez Flórez, A., “Comentario de la Ley...”, op. cit., pp. 1143 y 1144, se refiere al cumplimiento y la posibilidad de ejercitar la exceptio non rite adimpleti contractus, al señalar: "Además de válido, el cumplimiento tiene que ser regular y exacto (artículo 1.157 CC) Si una de las partes ha realizado la prestación al tiempo de la declaración de concurso, pero no se ha ajustado al programa de prestación establecido en el contrato, habrá realizado una prestación inexacta o defectuosa, el interés del acreedor no habrá sido satisfecho y no quedará liberada. Estarán pendientes de ejecución entonces - si no se han cumplido antes de la apertura del concurso y así lo exige el acreedor- las obligaciones surgidas como consecuencia de la realización de dicha prestación defectuosa y que se dirigen a su corrección (deberes de reparación o de sustitución); amén en su caso, de la obligación de indemnizar los daños y perjuicios causados cuando los defectos sean imputables al deudor”. Señalando, a continuación: “...en efecto, las obligaciones a que queda sometido el contratante que ha realizado la prestación defectuosa son recíprocas de las de la otra parte (que todavía no ha cumplido las establecidas a su cargo), pues no son sino una prolongación de la obligación de realizar la prestación correctamente, que tratan de remediar la ruptura del sinalagma que supone la realización de una prestación defectuosa. Es por ello que el contratante que todavía no ha cumplido puede oponer la excepción de contrato cumplido defectuosamente frente al contratante que ha realizado la prestación defectuosa y que reclama el cumplimiento a la otra y en tanto los defectos no hayan sido corregidos".

${ }^{20}$ Finez Ratón, J. M., Los efectos..., op. cit., p. 95.

${ }^{21}$ Zafra Jiménez, A., "Vigencia de los contratos con obligaciones recíprocas", en Comentarios a la Legislación Concursal, Art. 61, coord. Alberto Palomar Olmeda, Dykinson, Madrid, 2003, p. 577; Mairata Laviña, J., "Los efectos del concurso en la Ley Concursal”, en Derecho Concursal, dir. García Villaverde, R., Alonso Ureba, A. y Pulgar Ezquerra, J.A. Dilex, Madrid, 2003, p. 312. 
Para evitar esto, y teniendo en cuenta que aunque el crédito que ostente el contratante in bonis sea contra la masa, no tiene del todo seguro su cobro, ya que si no existen bienes suficientes en el concurso o existen otros créditos con privilegios especiales, podrá ver amenazado parte o la totalidad del pago de su crédito ${ }^{22}$. Por esto, es vital reconocer plenos efectos a la exceptio non adimpleti contractus, pues además no afecta en nada el sistema de realización colectiva de los derechos de crédito que el procedimiento concursal impone.

La exceptio se limita a proteger a la parte in bonis de las reclamaciones que el órgano de administración del concurso pueda dirigirle cuando este, a su vez, no se encuentre en disposición de cumplir lo adeudado. Su pretensión de obtener la prestación acordada queda, entonces, paralizada hasta que no garantice la satisfacción, en los términos pactados, del interés de su contraparte.

Ahora bien, la declaración de concurso no constituye una declaración de incumplimiento de las obligaciones contractuales a cargo del deudor concursado. Si no se produce el cumplimiento de la prestación se deberá constatar el incumplimiento que da lugar a las consecuencias que admite el Código Civil español, es decir, se podrá exigir a que se atienda lo pactado o resolver el contrato; y, en ambos casos, reclamar los daños y perjuicios que procedan. En tal caso, como se ha dicho, sería titular de un crédito contra la masa, no concursal.

Por lo tanto, mientras no se produzca un incumplimiento por parte del concursado, la parte in bonis no es acreedora del concurso. Lo podrá ser, en el futuro, si la deudora concursada no cumple su obligación contractual.

De esta manera, si la parte in bonis, en esta situación, se ve demandada por el concursado por impago del precio, se podrá oponer la exceptio non adimpleti contractus o la de riesgo de incumplimiento.

Fundamenta también el ejercicio de la exceptio en caso de declaración de concurso de uno de los contratantes, el hecho de que no esté expresamente excluida esta posibilidad. Pero, además, a base de la regla de “quien puede lo más, puede lo menos”, si es posible el ejercicio de la resolución, con mayor razón se podrá ejercitar la excepción de contrato no cumplido ${ }^{23}$.

${ }^{22}$ La SAP de León de 27 de abril de 2011 (AC 2011/1310) se refiere sobre la característica de los créditos contra la masa, señalando: “...La característica básica de estos créditos es que son prededucibles y se abonan 'antes de proceder al abono de los créditos concursales' (art. 154.1 LC). Así pues, es importante destacar que, en principio, su pago no queda afectado por el concurso, pues han de satisfacerse 'de forma inmediata' a sus respectivos vencimientos cualquiera que sea el estado del concurso aunque hay limitaciones importantes de este principio general, pues 'no podrán iniciarse ejecuciones para hacerlos efectivos hasta que se apruebe un convenio, se abra la liquidación o transcurra un año desde la declaración del concurso sin que se hubiera producido ninguno de estos actos', lo que supone que la satisfacción no es tan inmediata y por otra parte el n 3 del art. 154 LC prevé que las deducciones para atender el pago de los créditos contra la masa se harán sobre los bienes y derechos no afectos al pago de los créditos con privilegio especial, y si el importe de esos bienes y derechos resulta insuficiente, lo obtenido se distribuirá entre todos los acreedores de la masa por el orden de sus vencimientos".

${ }^{23}$ En este sentido, García Vicente, J. R., "De los efectos sobre los contratos", en Comentarios de la Ley Concursal, Art. 61 coord. Rodrigo Bercovitz Rodríguez-Cano, vol. I, Artículos 1 a 115, Tecnos, Madrid, 2004, p. 696, al señalar: "Si el contratante in bonis puede ejercer la resolución por incumplimiento (remedio liberatorio) y el concursado puede ostentar además un derecho de retención, de naturaleza igualmente suspensiva 
Así, como ya hemos indicado, las facultades de las partes de solicitar la resolución del contrato no se ve afectado por el auto de declaración de concurso (artículo 62.1 LC). Es decir, en caso de incumplimiento posterior (o anterior), la parte que ha cumplido pueda solicitar la resolución del contrato; aunque la declaración de concurso implique poner fin a las acciones individuales y acumular todas ellas en el procedimiento concursal.

Sobre esto último, se debe tener presente que la acción de resolución ejercitada por un incumplimiento anterior a la declaración de concurso genera un crédito con cargo a la masa, es decir, un crédito concursal. No así el incumplimiento que se produce una vez declarado el concurso, pues en este caso el crédito es contra la masa ${ }^{24}$.

\section{LIMITACión DE LA EXCEPTIO ANTE LA RESOLUCióN DEL CONTRATO DECLARADA POR EL JUEZ}

Como hemos indicado, el juez, frente a la solicitud del concursado en caso de intervención o de la administración concursal en la situación de suspensión, podrá declarar resuelto el contrato sin que exista incumplimiento en el interés del concurso ${ }^{25}$.

Conocemos la posibilidad que asiste a una de las partes del contrato a oponerse a la resolución mediante el ejercicio de la excepción de contrato no cumplido, pues sabemos que, para pedir la resolución, es necesario que exista al menos el incumplimiento de una de las partes del contrato. Por lo tanto, el excipens podría detener la acción resolutoria ejercida por aquella parte que no ha dado cumplimiento con su prestación.

La Ley Concursal en su artículo 61.2 viene a constituir una verdadera excepción al principio antes señalado, y, por lo mismo, lo es también para el ejercicio de la excepción de contrato no cumplido frente a la acción resolutoria. En este caso no podrá alegar la excepción de contrato no cumplido, debido a que el juez conociendo que el concursado no ha dado cumplimiento a su prestación podrá declarar resuelto el contrato en interés del concurso.

Cabe precisar, como ya señalamos, que no es el juez quien, de oficio, declara la resolución del contrato, sino que la legitimación para solicitarla ante la magistratura corresponde al concursado, según los artículos 22, 26 y 40 LC, si este conserva las facultades de administración y disposición de su patrimonio, o a la administración concursal, si el deudor-concursado tiene suspendido el ejercicio de las facultades de administración y disposición de su patrimonio.

Además, es interesante precisar que tanto el concursado como la administración concursal están obligados a solicitar la resolución del contrato si así lo demuestra el

(configurado como un derecho de separación, art. 80.1 LC), no hay razón para negarles la posibilidad de rehusar la reclamación del cumplimiento cuando exista riesgo de perder la contraprestación)”.

${ }^{24}$ Así, entre otras, las sentencias de los juzgados de lo mercantil núm. 1 de Bilbao de 24 de febrero de 2006 (AC 2006/139), núm. 1 de Oviedo de 3 de febrero de 2006 (JUR 2006/68797) y de 13 de marzo de 2006 (ADCo, núm. 9, 2006, pp. 347-349).

${ }^{25}$ Respecto de qué entiende la doctrina sobre el interés del concurso vid. Aznar Giner, E., La resolución del contrato en interés..., op. cit., p. 19. 
interés del concurso. Por ende, no se trata de una facultad que les permita elegir entre el cumplimiento o la resolución.

Aznar Giner ${ }^{26}$, quien comparte la opinión de Martínez Flórez ${ }^{27}$, afirma que “...la razón de que la ley se refiera a la resolución en interés del concurso en términos de facultad y no de obligación se debe, seguramente, por un lado, a que con semejante medida trata de excepcionar la regla establecida inmediatamente antes de que la declaración de concurso, por sí sola, no afecte a la vigencia de los contratos con obligaciones recíprocas pendientes de cumplimiento. Y, de otro, a que la presentación de dicha solicitud no es un acto que haya de realizarse necesariamente, sino solo cuando sea conveniente para los intereses del concurso".

La no solicitud de la resolución en interés de concurso trae, además, ciertas consecuencias para los administradores concursales. En este sentido, a la administración concursal se le podrá exigir la responsabilidad oportuna, al amparo del artículo 36 de la $\mathrm{LC}^{28}$, y para el concursado en caso de que este mantenga las facultades de administración cabe la posibilidad de cambio de su situación en el concurso, de intervención o suspensión de facultades, como también la calificación de su concurso como culpable, en la medida en que la falta de resolución suponga una agravación del estado de insolvencia (art. 164.1 LC) ${ }^{29}$.

\section{Resolución acordada por las partes}

Ante la solicitud de resolución de la administración concursal o del concursado (según haya suspensión o intervención, cfr. art. 40 LC), el secretario judicial citará a comparecencia ante el juez a la concursada, a la administración concursal y al contratante in bonis. De existir acuerdo entre ellos, en punto a la extinción del contrato y a los efectos de este, el juez dictará un auto declarando resuelto el contrato de conformidad con lo acordado por las partes. En caso de producirse la resolución por acuerdo de las partes, lo que verdaderamente existe es una verdadera transacción judicial ${ }^{30}$, con lo cual esta ya

${ }^{26}$ Aznar Giner, E., La resolución del contrato en interés..., op. cit., p. 33.

${ }^{27}$ Martínez Flórez, A., "Vigencia de los contratos con obligaciones recíprocas", en "Comentario de la Ley de Concursal”, Artículo 61, dir. Á. Rojo y E. Beltrán, Aranzadi, Madrid, 2004, pp. 1149 y 1150. Así también, Monserrat Valero, A., "Los efectos generales de la declaración de concurso sobre los contratos bilaterales", op. cit., p. 90 y Roca i Trías, E., "Eficacia e ineficacia de los contratos en el concurso del deudor", en Aspectos civiles de derecho concursal, XVI Jornadas de la Asociación de Profesores de Derecho Civil, Servicios de Publicaciones, Murcia, 2009, p. 45.

${ }^{28}$ El artículo 36.1 de la Ley Concursal señala: "Los administradores concursales y los auxiliares delegados responderán, frente al deudor y frente a los acreedores, de los daños y perjuicios causados a la masa por los actos y omisiones contrarios a la ley o realizados sin la debida diligencia”.

${ }^{29}$ Aznar Giner, E., La resolución del contrato en interés..., op. cit., p. 34.

${ }^{30}$ Clemente Meoro, M. E., "Los efectos de la declaración de concurso del comprador en la compraventa de inmuebles sometida a condición resolutoria por impago del precio”, ADCo, núm. 10, 2007-1, p. 210; Blasco Gascó, F., Declaración en concurso..., op. cit., p. 50 y 53; Aznar Giner, E.: La resolución del contrato en interés..., op. cit., p. 41. Como señala García Vicente, J. R.: "Seguros de caución o avales por cantidades percibidas a cuenta y concurso del promotor”, en García-Cruces, J.A. (dir.), Crisis Inmobiliaria y Derecho concursal, Aranzadi, 
no sería un verdadero supuesto que limitaría el ejercicio de la excepción de contrato no cumplido, porque es el propio acreedor que ha concurrido con su voluntad legitimando la resolución del contrato.

Como señala Estruch Estruch ${ }^{31}$, “...en realidad, lo que hace el juez es homologar el acuerdo de resolución alcanzado en la comparecencia por las partes”, agregando a continuación que "aunque la ley señala que el secretario judicial deberá citar a una comparecencia a las partes y, a la vista del resultado de la misma, el juez dictará auto declarando resuelto el contrato, lo cierto es que, en principio, el juez queda vinculado por la decisión de las partes, de tal manera que si estas quieren resolver el contrato y llegan a un acuerdo sobre sus efectos, tendrá que dictar un auto en este sentido a menos que exista fraude de ley o de tercero, o dicho acuerdo contraríe el orden público (arts. 6 y 1809 y ss. CC)”.

\section{Resolución decidida por el juez}

Si las partes no pueden ponerse de acuerdo en la resolución del contrato, o bien en los efectos de la misma, ya sea en la propia comparecencia que tiene prevista la Ley Concursal o antes de la misma, es el juez quien deberá resolver sobre dicha resolución o sobre sus efectos, por medio del incidente concursal acordando, en su caso, las restituciones que procedan y la indemnización que haya de satisfacerse con cargo a la masa.

Estamos en este caso ante una verdadera limitación al ejercicio de la exceptio non adimpleti contractus, ya que al decidir el juez en el incidente la resolución del contrato, ya no podrá el contratante in bonis oponerse a la resolución por la falta de cumplimiento de las obligaciones del concursado. Es una situación excepcional que se justifica, como ya hemos indicado, por el interés del concurso. El excipens ya no podrá seguir adelante con la ejecución del contrato estando obligado a obedecer lo resuelto por el juez.

\section{LIMITACIÓN DE LA EXCEPTIO NON ADIMPLETI CONTRACTUS EN EL SUPUESTO DEL ARTÍ́CULO 62.3 LC}

Como ya señalamos, el juez, en el interés del concurso, puede determinar seguir adelante con la ejecución del contrato, pese a que el concursado haya incumplido y el contratante in bonis haya ejercitado la acción resolutoria para poner fin a la relación

\footnotetext{
Pamplona, 2009, p. 195, normalmente la administración concursal o la concursada solicitará la resolución del contrato en "aquellos casos en los que el coste del incumplimiento actual sea menor que el beneficio esperado con un contrato de reemplazo". Por su parte, Fuentes Devesa, R., "Cuestiones procesales de la resolución de los contratos en el concurso", RDCP, núm. 10, 2009, p. 199, entiende que se deberá solicitar la resolución voluntaria del contrato cuando: “...resulte económicamente perjudicial el mantenimiento del vínculo contractual desde la óptica del concurso, al ser el coste de cumplimiento superior al valor de lo que se obtenga del mismo o hayan devenido innecesarios o excesivos para la actividad económica del concursado, ya por haber cesado ya por haberse reestructurado, o dificulten una solución convenida o liquidación adecuada”.

${ }^{31}$ Estruch Estruch, J., El comprador de vivienda ante el concurso del promotor, Civitas, Navarra, 2011, p. 37.
} 
contractual. En este evento, las prestaciones debidas serán con cargo a la masa ${ }^{32}$. En efecto, si la parte in bonis se encuentra privada por decisión judicial de su facultad resolutoria ante el incumplimiento del concursado, con razón también no se le permitirá enervar la solicitud de cumplimiento del contrato por parte de la autoridad judicial.

Cabe indicar de esta forma que la exceptio queda cercenada en su uso, quedando la parte in bonis a merced de lo que determine el juez en el interés del concurso. Si se concluye que el contrato debe llevarse a cabo y cumplirse pese al incumplimiento previo del concursado, la parte in bonis deberá esperar que se cumpla la prestación que se le adeude con cargo a la masa ${ }^{33}$.

El interés del concurso se justifica en el objetivo de la administración concursal de mantener la actividad empresarial y, por ende, los mínimos de producción que permitan la viabilidad del negocio, si es este el fin marcado por la administración concursal. Así se puede ver además en algunas resoluciones judiciales ${ }^{34}$, en cuyas fundamentaciones suele asomar el "interés del concurso" para justificar el mantenimiento de un contrato, a pesar del incumplimiento de las obligaciones del concursado, cuando se considera necesario o conveniente para la continuación de la actividad empresarial.

32 Sánchez Paredes, M. L. "Los contratos bilaterales pendientes en el concurso", op. cit., p. 450, al respecto indica: "La norma establece que aunque exista causa de resolución, el juez, atendiendo al interés del concurso, podrá acordar el cumplimiento del contrato, siendo a cargo de la masa las prestaciones debidas o que deba realizar el concursado. Así, aunque concurra un incumplimiento contractual grave y esencial, capaz de frustrar el fin del negocio, y ya proceda la iniciativa resolutoria de la parte in bonis o del concursado -o administración concursal, en su caso-, el juez podrá enervar dicha acción si estima que al interés del concurso conviene la continuación del contrato".

${ }^{33} \mathrm{Al}$ respecto, García Vicente, J. R. "El mantenimiento de los contratos de tracto sucesivo en el interés del concurso", ADCo, núm. 13, 2008, p. 353, señala: "Por último, en virtud del artículo 62.3, el contratante in bonis soporta el sacrificio de un contrato en vigor, pero sin gozar de sus facultades defensivas respecto de los incumplimientos anteriores, puesto que, según el Derecho común de contratos, hubiera podido oponer la excepción de contrato no cumplido para suspender el cumplimiento ulterior. No tendría buen sentido admitir la excepción de incumplimiento cuando se ha negado la facultad de resolver e impuesto el mantenimiento del contrato".

${ }^{34}$ Así la sentencia de la Audiencia Provincial de Valencia de 13 de octubre de 2010 (JUR 2011/43231), que conociendo un recurso de apelación interpuesto por la demandante, que solicitaba ante el juez de primera instancia la resolución del contrato al promotor por el incumplimiento en la entrega de la vivienda en el plazo pactado. La sentencia del juzgado de lo mercantil 2, Valencia, desestima la demanda por ser de interés del concurso el mantenimiento del contrato, debido a la práctica finalización de la vivienda. La Audiencia Provincial de Valencia, conociendo el recurso de apelación, mantiene lo resuelto por el juez de primera instancia indicando entre otras cosas lo siguiente: "Resulta indudable que cuando se presenta la demanda existe causa de resolución del contrato, al haber traspasado el límite temporal pactado, incluida la prórroga concedida para resolver el contrato más de nueve meses; con lo que solo el interés del concurso dispuesto legalmente puede enervar tal resolución y al caso entendemos que la razón fáctica dada por el juzgador, expuesta en el precedente fundamento, es de ratificar por este Tribunal, como ya ha hecho en otros supuestos semejantes al presente, y respecto de la misma promoción inmobiliaria y con iguales circunstancias fácticas (Rollo 241/2010 sentencia de 7-7-2010), y es que el estado avanzado de construcción cuando se interpone la demanda aconsejan dada su inmediata finalización el mantenimiento del contrato, pues resulta apreciable el interés del concurso porque si el contrato es de venta de bienes inmuebles (viviendas), actividad propia del objeto social de la entidad vendedora (concursada) y de la que se nutre sus activos con los que debe satisfacerse la masa pasiva del concurso, resulta de concluir que el interés del concurso ante esa tesitura no es la resolución del contrato de compraventa sino su mantenimiento, procediendo la confirmación de la decisión del Juzgado de lo Mercantil”. 
Por otro lado, parece que si el contrato continúa por decisión judicial, el acreedor in bonis conserva la facultad resolutoria que se ejercerá si se ven nuevamente incumplidas las prestaciones a cargo de la masa ${ }^{35}$. Por lo mismo, el contratante in bonis podrá también ejercitar la excepción de contrato no cumplido, en caso que no se ejecuten las prestaciones establecidas en el contrato que se ha decidido mantener.

\section{OpOSICIÓN DE LA EXCEPTIO POR RIESGO DE INCUMPLIMIENTO}

Se deduce de algunas disposiciones del Código Civil español, como los artículos $1.467^{36}$ y $1.502^{37}$, la posibilidad de ejercitar la excepción por riesgo de incumplimiento. Es decir, el excipens puede negarse a cumplir su propia prestación respecto de aquellas obligaciones recíprocas de vencimiento sucesivo, por el temor fundado de que su contraparte no llegue a cumplir su propia prestación.

Pues bien, la declaración de concurso es un supuesto específico que podría justificar el no cumplimiento, ya que como sabemos, en caso de que proceda a su cumplimiento, su contraprestación (crédito) estará a cargo de la masa pasiva del procedimiento concursal, dejando en suspenso la obtención de dicho crédito según la clase de crédito y a la existencia suficiente de bienes del cual se permita obtener su pago ${ }^{38}$.

Otros autores sostienen que no se puede mantener, de forma tan tajante, que la declaración de concurso sea una causa para poder entender que exista riesgo de incumplimiento $^{39}$. Fundando su opinión que debe tenerse en cuenta la situación de la masa concursal, en el sentido de que existan fundados elementos para temer que vaya a existir insuficientes activos para hacer frente a las deudas con cargo a la masa, y, en particular, a las prestaciones que se le deban al contratante no concursado. Solo en este caso sería posible negarse a seguir cumpliendo.

${ }^{35}$ Martínez Flórez, A., "Vigencia de los contratos con obligaciones recíprocas", en Comentario de la Ley de Concursal, Artículo 61, op. cit., p. 1169. Así también Monserrat Valero, A., "Los efectos generales de la declaración de concurso sobre los contratos bilaterales", op. cit., p. 117.

36 El artículo 1467 del Código Civil español indica: "Tampoco tendrá obligación el vendedor de entregar la cosa vendida cuando se haya convenido en un aplazamiento o término para el pago, si después de la venta se descubre que el comprador es insolvente, de tal suerte que el vendedor corre inminente riesgo de perder el precio. Se exceptúa de esta regla el caso en que el comprador afiance pagar en el plazo convenido".

${ }^{37}$ El artículo 1502 del Código Civil español señala: "Si el comprador fuere perturbado en la posesión o dominio de la cosa adquirida, o tuviere fundado temor de serlo por una acción reivindicatoria o hipotecaria, podrá suspender el pago del precio hasta que el vendedor haya hecho cesar la perturbación o el peligro, a no ser que afiance la devolución del precio en su caso, o se haya estipulado que, no obstante cualquiera contingencia de aquella clase, el comprador estará obligado a verificar el pago".

${ }^{38}$ García Vicente, J. R., "De los efectos sobre...”, op. cit., p. 695, al respecto señala: "La simple declaración de concurso configura el riesgo de incumplimiento y si bien no cabe convencionalmente se establezca como causa de resolución (art. 61.3 L.C.) sí puede ser suficiente para justificar la excepción, remedio suspensivo (puramente temporal) que no impide el cumplimiento o resolución posterior, sino que se trata de prevenir un perjuicio eventual". Diez Soto, C. M., Concurrencia y prelación de créditos: teoría general, Reus, Madrid, 2006, p. 65.

${ }^{39}$ Navarro Castro, M., Los créditos contra la masa..., op. cit., p. 122 y 123; Bonardell Lenzano, R., Régimen de los contratos sinalagmáticos en el concurso, Tirant lo Blanch, Valencia, 2006, p. 63. 
Se debe además considerar que la parte que celebró el contrato con el concursado con fecha anterior a la declaración del concurso no es propiamente acreedor concursal sino hasta que se incumpla por el concursado una de las prestaciones establecidas en el contrato. Si aún no se ha incumplido las obligaciones que establece el contrato por el concursado, no deberían tener el carácter de acreedor concursal, salvo que se demuestre que el cumplimiento del concursado es imposible de ejecutar. Por lo tanto, es perfectamente posible que las obligaciones que impone el contrato al concursado se puedan ir cumpliendo con cargo a la masa. Es por esto que, en realidad, mientras el deudor concursado vaya cumpliendo sus obligaciones con cargo a la masa, como exige el artículo 61.2 LC, el acreedor no tiene ningún derecho de crédito que reclamarle al concursado, ni contingente ni actual, ni ha visto vulnerada ninguna posición jurídica por el concurso ${ }^{40}$.

En este sentido se pronuncia la sentencia del juzgado mercantil $\mathrm{N}^{\circ} 1$ de Bilbao de 21 de septiembre de $2009^{41}$, que resuelve la impugnación de la lista de acreedores formulada por los compradores de una vivienda que debía entregarse 42 meses después de la firma del contrato de compraventa (que fue en 2008), debido a que la administración concursal no los había incluido en dicha lista. Frente a esta reclamación, la sentencia entiende que, en el momento de la fecha de la declaración del concurso, los compradores no son acreedores de la concursada, pues el contrato se encuentra pendiente de cumplimiento por ambas partes y debe aplicarse al mismo lo dispuesto en el art. 61.2 LC. En efecto, la sentencia señala: "La pretensión de los acreedores es que su crédito es concursal. Sin embargo, admiten que se trata de un contrato con obligaciones recíprocas pendientes de cumplimiento por ambas partes. Es decir, el supuesto regulado en el art. 61.2 LC, que ha previsto que no se vean afectados por la simple declaración de concurso, coherente con la previsión del art. 44 que dispone la continuidad de la actividad empresarial. Un contrato de compraventa como los aportados por la administración concursal con su contestación no pueden situarse en la previsión del art. 61.1 LC, porque ninguna de las partes ha cumplido íntegramente sus obligaciones. Ni el comprador ha satisfecho la totalidad del precio, ni el vendedor ha entregado aún la vivienda. Por el contrario, hay obligaciones recíprocas pendientes, pago del precio y entrega de la vivienda, en el momento que se declaró el concurso. Esto supone, al menos mientras no se acuerde el cese de la actividad, que el comprador debe seguir atendiendo el precio en los plazos previstos, y el vendedor tendrá que continuar la edificación, con cargo a la masa, en cumplimiento de sus obligaciones contractuales, situación que la doctrina ha definido como "contrato de la masa". Como dice la administración concursal, no hay crédito alguno, porque nada se adeuda, hasta que llegue el término convenido, a los compradores. No obstante, habrá que matizar que es preciso que la concursada continúe, en cumplimiento de su contrato, la promoción inmobiliaria que ha comprometido en el municipio cántabro de Colindres. Si después de declarado el concurso no lo hiciera (los incumplimientos anteriores en contratos de tracto sucesivo,

${ }^{40}$ Estruch Estruch, J., El comprador de vivienda ante ... op. cit., p. 32.

41 (AC 2009/2026). En este mismo sentido, se pronuncian la SJM núm. 1 de Bilbao de la misma fecha, 21 de septiembre de 2009 (AC 2009/2028) y SJM núm. 1 de A Coruña de 12 de marzo de 2010 (JUR 2010/261764) 
cualidad que no es propia de la compraventa), los compradores quedarían habilitados para instar la resolución de los contratos por incumplimiento, conforme al art. 62.1 LC, convirtiéndose efectivamente en acreedores, pero a la restitución de las cantidades que procedan e indemnización de daños y perjuicios, conforme a los arts. 1124 y 1504 del Código Civil, crédito a la restitución que el art. 84.2.6 $6^{\circ}$ LC considera contra la masa".

Posteriormente, la sentencia concluye, respecto de la situación de los compradores, indicando: "Como consecuencia de todo lo dicho hasta aquí hay que concluir que los demandantes no son acreedores del concurso, al menos en estos momentos. Lo serán en el futuro, si la deudora concursada no cumple su obligación contractual, la entrega de los inmuebles objeto de los distintos contratos de compraventa en las fechas convenidas. Pero la declaración de concurso no constituye una declaración de incumplimiento de las obligaciones contractuales a cargo del deudor concursado. Los riesgos que anuncia la demanda son conjurados por la regulación de la Ley Concursal y el Código Civil, en materia de obligaciones y contratos. Si los compradores se ven demandados por el concursado por impago del precio, podrá oponer las correspondientes excepciones de contrato no cumplido, no debidamente cumplido y, en una situación concursal como la presente, de riesgo de incumplimiento. Atendiendo al régimen general de las obligaciones del Código Civil, no hay razón para temer que el deudor concursado no cumpla y sin embargo pretenda exigir que lo hagan los compradores”.

Por esto, la excepción por riesgo de incumplimiento en materia de derecho concursal será más fácil de ser admitida cuando el excipens ya tenga la calidad de acreedor concursal, es decir, que existan prestaciones vencidas que puedan exigir a la administración concursal. Solo en este caso se justificaría que el deudor in bonis se oponga al cumplimiento de sus obligaciones, ya que al encontrarse vencidas las prestaciones del concursado, existe un riesgo real de que si cumple el deudor in bonis con su obligación no reciba nada a cambio. Hasta que no se llegue a este punto, no parece lógico que el deudor in bonis se oponga al cumplimiento; y tendrá éxito o no la excepción por riesgo de incumplimiento, según las circunstancias que se demuestre en que se encuentre el concursado en relación con la posibilidad o no de cumplir con las prestaciones que aún debe.

\section{CONCLusiones}

La ley no contiene mención alguna sobre la utilización por el contratante in bonis de las excepciones de contrato no cumplido, defectuosamente cumplido o de riesgo de incumplimiento. Respecto de los dos primeros supuestos creemos que es posible ejercerla, sobre todo teniendo en cuenta que el artículo 61 LC señala que la declaración de concurso no afectará a la vigencia de los contratos con obligaciones recíprocas ${ }^{42}$. Sobre el último supuesto, si bien existen en la doctrina diferentes criterios para su admisión,

42 Martínez Rosado, J., "Los efectos de la declaración de concurso sobre los contratos con obligaciones recíprocas (arts. 61 a 63 de la Ley 22/2003, de 9 de julio, Concursal)”, en Estudios sobre la Ley Concursal. Libro homenaje a Manuel Olivencia, vol. III, Marcial Pons, Madrid, 2005, p. 2969. 
entendemos que su uso encuentra fundamento en normas generales del Código Civil español (artículos 1.129 y 1.467 del CC).

Sostenemos que es el juez quien deberá estimar fundada o no la excepción por riesgo de incumplimiento, según la situación en que se encuentre la masa concursal y las verdaderas posibilidades de poder obtener posteriormente el cumplimiento. Si existe el mínimo riesgo, no hay razones para pensar que no se pueda poner en ejercicio.

Es de justicia y equidad conceder la excepción a la parte que se le exige el cumplimiento, si tenemos en cuenta que la administración concursal o el concursado están en la posición de solicitar la resolución del contrato, sin que el contratante in bonis haya incumplido siquiera su parte.

Además, justifica el ejercicio de la excepción de contrato no cumplido si tenemos en cuenta que en nada se perjudica a la masa concursal, toda vez que ambas prestaciones se encuentran pendientes de cumplimiento.

\section{BIBLIOGRAFÍA}

Etxarandio Herrera, E.J., Manual de Derecho Concursal, La Ley, Madrid, 2009.

Finez Ratón, J.M., "De los efectos sobre los contratos”, en Tratado Práctico Concursal, Tomo II, Efectos de la Declaración de Concurso, Aranzadi, Navarra, 2009, pp. 625 y sgtes.

Finez Ratón, J.M., Los efectos de la declaración de quiebra en los contratos bilaterales, Civitas, Madrid, 1992.

Fuentes Devesa, R., "Cuestiones procesales de la resolución de los contratos en el concurso", RDCP, núm. 10, 2009.

García Vicente, J.R., "De los efectos sobre los contratos", en Comentarios de la Ley Concursal, Bercovitz Rodríguez-Cano (Coord.), Vol. I, Artículos 1 a 115, Tecnos, Madrid, 2004.

García Vicente, J.R., "El mantenimiento de los contratos de tracto sucesivo en el interés del concurso", ADCo, núm. 13, 2008.

García Vicente, J.R., "Seguros de caución o avales por cantidades percibidas a cuenta y concurso del promotor", en García-Cruces, J.A. (dir.), Crisis Inmobiliaria y Derecho concursal, Aranzadi, Pamplona, 2009.

Gómez MendozA, M., "Vigencia de los contratos con obligaciones recíprocas", en Comentarios a la legislación concursal (Ley 22/2003 y 8/2003 para la reforma concursal), AA.VV. dirigidos por Pulgar Ezquerra, J., Alonso Ledesma, C., Alonso Ureba A., y Alcover Garau G., Tomo I, Dykinson, Madrid, 2004.

Hernández Martí, J., "Efectos de la declaración del concurso: efectos sobre los contratos", Concurso e insolvencia punible, Tirant lo Blanch, Valencia, 2004.

Mairata Laviña, J., "Los efectos del concurso en la Ley Concursal", en Derecho Concursal, R. García Villaverde, A. Alonso Ureba y J.A Pulgar Ezquerra (dir.), Dilex, Madrid, 2003.

Martínez Flórez, A., "Comentario de la Ley de Concursal", Articulo 61, Á. Rojo y E. Beltrán (dir.), Aranzadi, Madrid, 2004, pp. 1143 y sgtes.

Martínez Flórez, A., "Vigencia de los contratos con obligaciones recíprocas", en Comentario de la Ley Concursal, Artículo 61, dir. Á. Rojo y E. Beltrán. Aranzadi, Madrid, 2004.

Martínez Rosado, J., "Los efectos de la declaración de concurso sobre los contratos con obligaciones recíprocas (arts. 61 a 63 de la Ley 22/2003, de 9 de julio, Concursal)”, en Estudios sobre la Ley Concursal. Libro bomenaje a Manuel Olivencia, Vol. 3, Marcial Pons, Madrid, 2005. 
Moreno Sánchez-Moraleda, A., Los efectos de la declaración de concurso en los contratos bilaterales, Tirant lo Blanch, Valencia, 2010.

Monserrat Valero, A., "Los efectos generales de la declaración de concurso sobre los contratos bilaterales", ADCo, 2008, núm. 12.

Navarro Castro, M., Los créditos contra la masa en el concurso de acreedores, Reus, Madrid, 2008.

Roca I Trías, E., "Eficacia e ineficacia de los contratos en el concurso del deudor", en Aspectos civiles de derecho concursal, XVI Jornadas de la Asociación de Profesores de Derecho Civil, Servicio de Publicaciones, Murcia, 2009.

Sánchez Calero, F., Instituciones de Derecho Mercantil, II, McGraw-Hill, Madrid, 2002.

SÁnchez Paredes, M.L., "Los contratos bilaterales pendientes en el concurso", ADCo, núm. 18, 2009.

Serra Rodríguez, A., "El 'interés del concurso' en la Ley 22/2003, de 11 de julio, concursal”, en La dialettica degli interessi disciplina delle societá per anzioni, Jovene Editore, Nápoles, 2011.

Trujillo Diez, I.J., Los efectos del concurso sobre el contrato de cuentas corrientes, Aranzadi, Navarra, 2003.

VÁsquez Iruzubieta, C., Comentarios a la Ley Concursal, Art. 61, Dijusa, Madrid, 2003.

Vicente y Gella, A., Curso de Derecho Mercantil Comparado, Tip. La Académica, Zaragoza, 1960.

Zafra Jiménez, A., "Vigencia de los contratos con obligaciones recíprocas", en Comentarios a la Legislación Concursal, Art. 61, Palomar Olmeda, A. (coord.), Dykinson, Madrid, 2003. 
